\title{
Toll-like receptor agonists shape the immune responses to a mannose receptor-targeted cancer vaccine
}

\author{
Li-Zhen He ${ }^{1}$, Jeffrey Weidlick ${ }^{1}$, Crystal Sisson ${ }^{1}$, Henry C Marsh ${ }^{2}$ and Tibor Keler ${ }^{1}$
}

Previous studies have documented that selective delivery of protein antigens to cells expressing mannose receptor (MR) can lead to enhanced immune responses. We postulated that agents that influenced the MR expression level, and the activation and migration status of MR-expressing antigen presenting cells, would modulate immune responses to MR-targeted vaccines. To address this question, we investigated the effect of clinically used adjuvants in human MR transgenic (hMR-Tg) mice immunized with an MR-targeting cancer vaccine composed of the human anti-MR monoclonal antibody B11 fused with the oncofetal protein, human chorionic gonadotropin beta chain (hCGß), and referred to as B11-hCG found that humoral responses to low doses of B11-hCG $\beta$ could be enhanced by prior administration of GM-CSF, which upregulated MR expression in vivo. However, co-administration of the Toll-like receptor (TLR) agonists, poly-ICLC and/or CpG with B11-hCG $\beta$ was required to elicit Th1 immunity, as measured by antigen-specific T-cell production of IFN- $\gamma$. The TLR agonists were shown to increase the number of vaccine-containing cells in the draining lymph nodes of immunized hMR-Tg mice. In particular, with B11-hCG $\beta$ and poly-ICLC, a dramatic increase in vaccine-positive cells was observed in the T-cell areas of the lymph nodes, compared to the vaccine alone or combined with GM-CSF. Importantly, the absence of the TLR agonists during the priming immunization led to antigen-specific tolerance. Therefore, this study provides insight into the mechanisms by which adjuvants can augment immune responses to B11-hCG $\beta$ and have implications for the rationale design of clinical studies combining MR-targeted vaccination with TLR agonists.

Cellular \& Molecular Immunology (2015) 12, 719-728; doi:10.1038/cmi.2014.100; published online 27 October 2014

Keywords: GM-CSF; hCG $\beta$; mannose receptor; Toll-like receptor agonists

\section{INTRODUCTION}

Proteins can be effectively formulated to induce humoral immunity, but new approaches to improve cellular immunity, particularly for weakly immunogenic antigens, are required for developing more effective cancer and infectious disease vaccines. We have been working with a technology pioneered by $\mathrm{R}$ Steinman and $\mathrm{M}$ Nussenzweig that utilizes antibodies to deliver antigens directly to endocytic receptors on dendritic cells (DCs). ${ }^{1-4}$ This elegant method uses recombinant antibodies engineered with the antigen incorporated as a fusion protein that, in addition to targeting the antigen to antigen presenting cells (APCs), has the advantages of a standardized manufacturing process typical for monoclonal antibodies and a well-defined regulatory path. Previous studies have shown the potential for this approach to improve T-cell immunity to vaccines, but also highlighted the importance of utilizing adjuvants to enhance immunity and prevent tolerance. ${ }^{5-7}$

A number of C-type lectin receptors have been exploited for developing DC-targeted vaccines with promising results in various preclinical models. ${ }^{8-11}$ The majority of focus has been on DEC-205 (CD205), a molecule expressed on the $\mathrm{CD} 8^{+}$DC subset in mice. ${ }^{12,13}$ However, other members of this family, such as DC-SIGN,${ }^{14-16}$ Langerin, ${ }^{17} \mathrm{Clec} 9 \mathrm{~A}^{18}$ and $\mathrm{MR},{ }^{11,19}$ have also shown promising preclinical data with specific antibodies to each receptor. A recent study demonstrated that the targeted cellular subset $\left(\mathrm{CD}^{+} \mathrm{DC}\right)$ was more critical than the specific receptor itself, as targeting to DEC-205, Langerin, or Clec9A similarly enhanced Th1 immunity to an HIV antigen, while targeting to DCIR2 (expressed on $\mathrm{CD}^{-}$DC) was less effective. ${ }^{20}$ Additionally, the intracellular trafficking of the receptors may influence the efficiency of cross-presentation. Receptors such as mannose receptor (MR) that target early endosomes were shown to promote slower antigen degradation and better cross-presentation in human in vitro cultures than DEC-205 targeting, which resulted in rapid antigen degradation by delivery to late endosomes. ${ }^{21}$

Additional studies and insight are required to optimize this approach for human vaccination. To that end, we have

${ }^{1}$ Celldex Therapeutics, Inc., Hampton, NJ, USA and ${ }^{2}$ Celldex Therapeutics, Inc., Needham, MA, USA

Correspondence: Dr LZ He, Celldex Therapeutics, Inc., Perryville III Building, Suite 220, 53 Frontage Road, Hampton, NJ 08827, USA.

E-mail: Ihe@celldex.com

Received: 15 April 2014; Revised: 26 August 2014; Accepted: 15 September 2014 
developed vaccines for human studies targeting either DEC205 or MR, and have recently reported the data from the phase 1 trial of our MR-targeted oncofetal antigen, human chorionic gonadotropin beta chain (hCG $\beta$ ). ${ }^{22}$ This vaccine, referred to as B11-hCG $\beta$ or CDX-1307, is composed of hCG $\beta$ fused to the $\mathrm{MR}$-specific human monoclonal antibody $\mathrm{B} 11$. In vitro, the B11-hCG $\beta$ promoted the uptake and processing of hCG $\beta$ by human DC that, when activated with CD40 ligand, led to the expansion of autologous hCG $\beta$-specific MHC class I- and class II-restricted T cells, including CTL capable of lysing human cancer cell lines that expressed hCG $\beta$ in vitro. ${ }^{23}$ The clinical study was performed in patients with advanced solid tumors that received the B11-hCG $\beta$ vaccine alone as well as in combination with single or multiple adjuvants including GM-CSF, the Toll-like receptor (TLR) 3 agonist poly-ICLC and the TLR7/8 agonist resiquimod. ${ }^{22}$ This first in man study demonstrated feasibility and a favorable safety profile for B11-hCG $\beta$, and correlated higher immune responses with clinical benefit when vaccination was combined with the local TLR agonists.

In this study, we have used our human MR transgenic (hMR-Tg) mouse model to assess the efficiency of MRmediated antigen uptake and better understand how adjuvants can shape the immune response to B11-hCG $\beta$. We have previously reported that targeting the model antigen ovalbumin to human MR in hMR-Tg mice induced protective immunity against an ovalbumin-expressing tumor when combined with the TLR9 agonist $\mathrm{CpG}$ oligodeoxynucleotide $(\mathrm{CpG}) .{ }^{19}$ Here we used our clinical vaccine B11-hCG $\beta$ and evaluated the effects of GM-CSF and two TLR agonists, poly-ICLC and CpG, on the in vivo distribution of the vaccine and the resulting immune responses. We found that GM-CSF upregulated the expression of MR and enhanced humoral but not Thl responses to B11-hCG $\beta$. Furthermore, poly-ICLC and CpG promoted the accumulation of B11-hCG $\beta$-loaded DCs in the T-cell areas of draining lymph nodes, which correlated with strong Th1 immunity.

\section{MATERIALS AND METHODS}

\section{Antibodies and reagents}

The anti-hMR antibody B11 was generated by immunizing human immunoglobulin transgenic mice with human mannose receptor. The monoclonal antibody $(\mathrm{mAb}) \mathrm{B} 11$ binds human mannose receptor, but not mouse mannose receptor. ${ }^{11}$ The B11-hCG $\beta$ fusion protein was generated by genetically coupling hCG $\beta$ to the carboxyl terminus of the B11 heavy chain, and clinical grade material was manufactured from transfected Chinese hamster ovary cells. ${ }^{22,23}$ The labeling of B11-hCG $\beta$ with Alexa-647 was performed according to the manufacturer's protocol (Invitrogen, Carlsbad, CA, USA). Antibodies for staining of CD3e (145-2C11), CD4 (H129.19), CD8 $\alpha$ (53-6.7), CD11c (HL3), MHC class II I-A/I-E (M5/114.15.2), F4/80 (BM8) and CD103 (2E7) were purchased from BD Biosciences (San Jose, CA, USA) or eBioscience (San Diego, CA, USA). hMR was stained with either B11 or 19.2 (BD Biosciences), mouse MR (mMR) with MR5D3, and DEC-205 with NLDC-145 (AbD Serotec, Raleigh, NC, USA and BMA Biomedicals, Augst, Switzerland). Mouse GM-CSF was from Peprotech (Rocky Hill, NJ, USA). Complete
Freund's adjuvant (CFA) was from Sigma-Aldrich (St. Louis, MO, USA). CpG (ODN1826) and polyinosinic-polycytidylic acid (poly-IC) were from InvivoGen (San Diego, CA, USA). PolyICLC (poly-IC stabilized with poly-lysine and carboxymethylcellulose) was supplied by Oncovir, Inc (Washington, DC, USA).

\section{Mice}

hMR-Tg mice on a C57BL/6 background were generated by BAC clone DNA microinjection and the transgene expression was directed by the native human promoter. ${ }^{19}$ Heterozygous hMR-Tg mice and age- and gender-matched wild-type (WT) mice between 6 and 15 weeks of age were used in all experiments. Mice were housed under specific pathogen-free conditions in our animal facilities and were treated and used in accordance with the guidelines established by the Institutional Animal Care and Use Committee at Celldex.

\section{Immunohistochemical (IHC) and immunofluorescence staining}

To visualize the location of the hCG $\beta^{+}$cells in skin and lymphatic organs, hMR-Tg mice were injected subcutaneously (s.c.) at the tail base with $10 \mu \mathrm{g}$ of B11-hCG $\beta$ plus or minus adjuvant as indicated. Skin near the injection site (local skin) and draining lymph nodes (inguinal) were collected $24 \mathrm{~h}$ later. The organs were OCT-snap frozen, sectioned, fixed and stained with rabbit anti-hCG $\beta$ (Dako, USA, Carpinteria, CA, USA) after blocking $\mathrm{F} c$ receptors with $\gamma$-globulin. A Dako EnVision Kit was used to reveal the immuno-binding and hematoxylin for counterstain. To define T-cell and B-cell areas, consecutive sections of draining lymph nodes were stained with Texas redlabeled anti-CD3e and anti-B220 antibodies (BD Biosciences) as well as the fluorescent dye 4',6-diamidino-2-phenylindole for cellular nuclei.

To examine the colocalization of hCG $\beta$ and hMR, local skin and draining lymph node sections were stained with rabbit anti-hCG $\beta$ and FITC-labeled mouse anti-hMR (clone 19.2; BD Biosciences), and followed with donkey anti-rabbit IgGCy3 (Jackson ImmunoResearch, West Grove, PA, USA) and Goat anti-FITC/Oregon green-Alexa488 (Invitrogen). For the colocalization of hCG $\beta$ and MHC class II, rabbit anti-hCG $\beta$ and biotinylated anti-mouse I- $\mathrm{A}^{\mathrm{b}}$ (BD Biosciences) were used as primary antibodies, and followed by goat anti-rabbit IgGAlexa488 and strepavidin-Cy3 (Jackson ImmunoResearch). Images were taken with a confocal microscope (Carl Zeiss, Cambridge, UK).

\section{In vivo $\mathrm{MR}$ regulation}

hMR-Tg mice and WT littermates were injected intraperitoneally (i.p.) with $1 \mathrm{ml}$ of $3 \%$ thioglycolate on day 1 , and s.c. with either $2 \mu \mathrm{g}$ of GM-CSF on days 2, 3 and 4 , or $20 \mu \mathrm{g}$ of poly-ICLC or $25 \mu \mathrm{g}$ of CpG on day 4. Peritoneal exudate cells (PECs) and bone marrow $(\mathrm{BM})$ were collected on day 5 . After BM was dissociated with 0.2 units $/ \mathrm{ml}$ of Liberase Blendzymes II (Roche Applied Science, Indianapolis, IN, USA), APC were enriched from BM by depleting lymphoid, myeloid and erythroid lineages with biotin-conjugated antibodies specific for 
CD3e, B220, Gr-1 and Ter119 (BD Biosciences) using streptavidin-coupled Dynabeads (Invitrogen). APC-enriched BM cells and PEC were incubated with the $\mathrm{F} c$ receptor blocker 2.4G2, then stained with anti-hMR (19.2-PE) or anti-mMR (MR5D3$\mathrm{PE})$. F4/80 mAb was included in PEC staining as a macrophage $(\mathrm{M} \Phi)$ marker. PEC intracellular hMR was also stained after cells were fixed and permeabilized with BD Cytofix/Cytoperm and BD Perm/Wash (BD Biosciences). Stained cells were acquired and analyzed on an LSR or FACSCanto II flow cytometer (BD Immunocytometry Systems, San Jose, CA, USA).

\section{Immunization}

hMR-Tg and WT mice were injected s.c. in the paws or i.p. with 1 or $10 \mu \mathrm{g}$ of B11-hCG $\beta$ in saline or mixed with adjuvant (polyICLC $20 \mu \mathrm{g} \pm \mathrm{CpG} 25 \mu \mathrm{g}$ ) for one or two doses as indicated in the figure legends. Blood samples were collected from the orbital sinus before and 1 week after each immunization, and the isolated plasmas were stored for ELISA. Spleens were harvested 7 or 14 days after the last injection to evaluate T-cell responses by ELISPOT.

\section{ELISA}

Anti-hCG $\beta$ antibody titers and subclasses were examined by standard ELISA. Microtiter plates were coated with $3 \mu \mathrm{g} / \mathrm{ml}$ of hCG $\beta$ (Meridian Life Science, Memphis, TN, USA) and HRPconjugated goat anti-mouse IgG Fc (Jackson ImmunoResearch Lab) or goat anti-mouse IgG1, IgG2a, IgG2b, IgG2c and IgG3 (Southern Biotechnology Associates, Birmingham, AL, USA) were used for detection. Mouse plasma was serially diluted and titers were determined by the highest dilution giving an $\mathrm{OD}_{450}$ greater than twice that of negative control plasma and were expressed as a log reciprocal dilution.

\section{ELISPOT}

IFN- $\gamma$ and IL-4 antibody sets were purchased from BD Biosciences. Splenocytes at $0.1 \times 10^{6}-1 \times 10^{6}$ per well in RPMIco medium (RPMI 1640 with 5\% FBS, $55 \mu \mathrm{M} \beta-\mathrm{ME}$, $1 \mathrm{mM}$ sodium pyruvate, 100 units/ml penicillin and $100 \mu \mathrm{g} /$ $\mathrm{ml}$ streptomycin) were dispensed in 96-well filtration plates that had been coated with capture antibody. A pool of peptides, 15 amino acids in length, overlapping by 11 amino acids and spanning the entire hCG $\beta$ sequence (synthesized by Synpep, Dublin, CA, USA), was added to a final concentration of $1.7 \mu \mathrm{g} /$ $\mathrm{ml}$ of each peptide and incubated at $37^{\circ} \mathrm{C}$ overnight. Detection was performed by following the $\mathrm{BD}$ Biosciences' protocol. The plates were analyzed by ZellNet Consulting, Inc. (Fort Lee, NJ, USA). The hCG $\beta$-specific spot number of each sample was calculated as the average of the triplicate peptide-treated wells after spots in wells in the absence of peptides were subtracted.

\section{Intracellular cytokine staining}

Splenocyte cultures were set up as for ELISPOT assay except using U-bottom 96-well tissue culture plates, stimulated with or without the hCG $\beta$ peptide pool in the presence of $2 \mu \mathrm{g} / \mathrm{ml}$ anti-CD28 mAb (clone 37.51, NA/LE format from BD Biosciences) for $5 \mathrm{~h}$. The Golgi secretion blocker Brefeldin A (Sigma-Aldrich) was added to cultures at final concentration of
$10 \mu \mathrm{g} / \mathrm{ml}$ for the last $4 \mathrm{~h}$. The cultured splenocytes were incubated with Live/Dead Fixable Aqua Dead Cell Stain Kit blue fluorescent dye (Invitrogen), blocked with CD16/CD32 antibody (2.4G2) and stained with anti-CD3e-FITC, anti-CD8 $\alpha$-PerCP Cy5.5. Cells were then fixed and permeabilized with BD Cytofix/Cytoperm solution and stained with PE- or APC-labeled anti-mouse IFN- $\gamma$ (clone XMG1.2 from BD Biosciences). At least 300000 live events per sample were acquired in BD FACSCanto II flow cytometer and analyzed with software FCS Express V3. The percentages of hCG $\beta$-specific IFN- $\gamma$-positive cells among $\mathrm{CD}^{+} / \mathrm{CD}^{-}$and $\mathrm{CD} 3^{+} / \mathrm{CD} 8^{+}$gated populations were obtained after subtracting the percentage in the absence of peptides.

\section{Characterization of B11-hCG $\beta$-targeted cells}

In order to characterize which populations of cells were effectively targeted by B11-hCG $\beta$, hMR-Tg and WT mice were injected s.c. in the paws with $5 \mu \mathrm{g}$ of Alexa647-labeled B11-hCG $\beta$ in $50 \mu \mathrm{l}$ saline per site (total $20 \mu \mathrm{g}$ per mouse) in the presence or absence of adjuvant as indicated. Draining lymph nodes (inguinal, brachial and axillary) were harvested $24 \mathrm{~h}$ later and pooled to prepare single cell suspensions. Aliquots of $1.5 \times 10^{6}$ cells were stained with four panels of antibodies after incubation with Pacific Blue fluorescence reactive dye (Invitrogen) and blocking $\mathrm{F} c$ receptors with 2.4G2: (i) hMR-PE, MHC II-FITC and CD11c-PerCP Cy5.5; (ii) hMR-FITC, CD8 $\alpha$-PerCP Cy5.5 and CD103-PE; (iii) hMR-PE and mMR-biotin, streptavidin-FITC; and (iv) DEC-205-FITC and mMR-biotin, streptavidin-PE. Because the majority of cellular MR is found within the endocytic pathway with only $15 \%$ of the cellular pool on the cell surface, ${ }^{24}$ and the surface hMR in our Tg mice was barely measurable by flow cytometry under naive conditions, hMR and mMR were stained after cells were fixed and permeabilized. A total of 800000 events were acquired on a BD FACSCanto II, and the total live cells (Pacific Blue-negative) and hCG $\beta$-containing cells were gated and analyzed.

\section{RESULTS}

\section{B11-hCG $\beta$ is efficiently delivered to MR-expressing cells in} hMR-Tg mice

To evaluate the in vivo targeting of the B11-hCG $\beta$ vaccine which recognizes human but not mouse $\mathrm{MR}$, we injected the fusion protein s.c. into hMR-Tg or WT mice and subsequently evaluated the distribution of the hCG $\beta$ in tissues using IHC. As shown in Figure 1a, prominent hCG $\beta$ staining was observed in the skin and draining lymph nodes of hMR-Tg mice but not WT mice. Further characterization of the antigen-positive cells in hMR-Tg mice was performed by dual staining for hCG $\beta$ with MR or MHC class II (Figure $1 \mathrm{~b}$ and c). Complete concordance with hCG $\beta$ antigen-positive and MR expression in both skin and lymph nodes was observed. These MR-positive cells are known to be dermal DCs, macrophages, lymph node interstitial DCs, capsular macrophages and sinusoidal endothelial cells. ${ }^{19,24-26}$ On the contrary, the dual staining of hCG $\beta$ and MHC class II revealed that a portion of these hCG $\beta$ positive cells (particularly in skin) was MHC class II-negative, indicating that a less mature macrophage population was also involved in antigen uptake. 
a

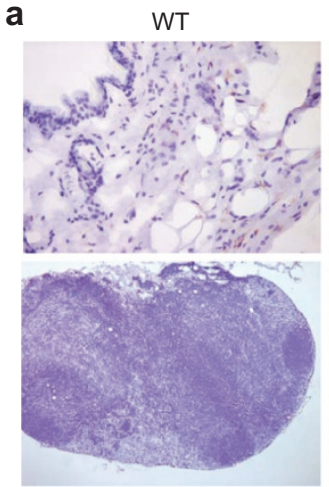

b
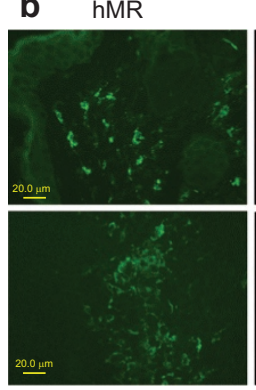

c $\mathrm{hCG} \beta$
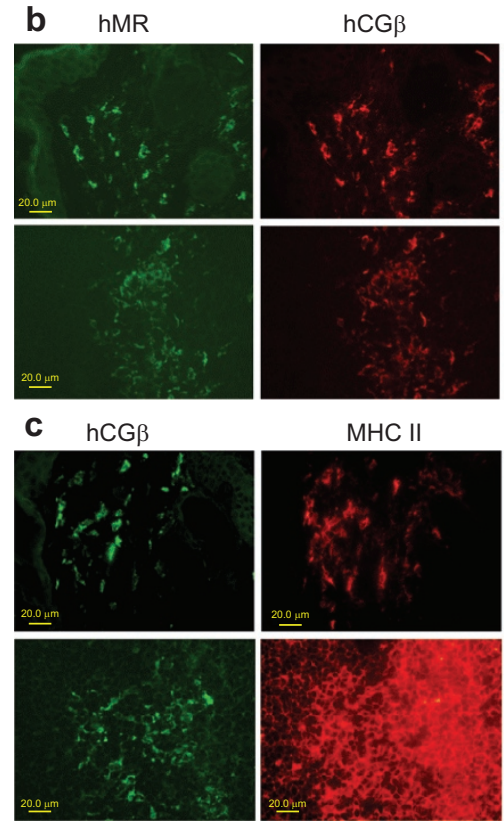

$\mathrm{MHC}$ II
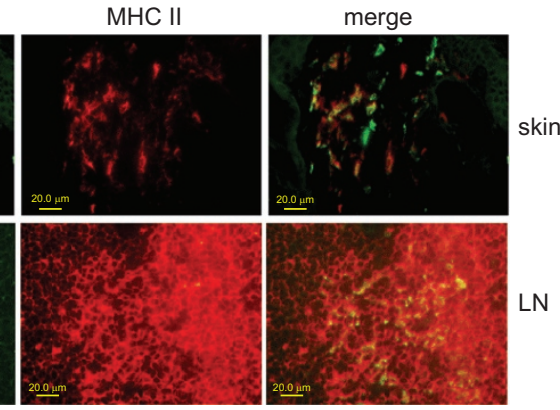

Figure 1 hMR-Tg and WT mice were injected s.c. at the tail base with $10 \mu \mathrm{g}$ of B11-hCG $\beta$. Local skin and inguinal LNs were collected $24 \mathrm{~h}$ later and cryopreserved. (a) hMR-mediated uptake of B11-hCG $\beta$. IHC was performed with rabbit anti-hCG $\beta$ IgG, Dako EnVision kit and hematoxylin counterstain. The images were taken with a $\times 20$ objective lens for skin and a $\times 4$ objective lens for $L N$. The inserted cropped $40 \times$ image in the upper right corner of the Tg LN frame shows the morphology of representative hCG $\beta$-positive cells in the LN. (b) Colocalization of hCG $\beta$ and hMR. Immunofluorescence dual staining was performed with rabbit antihCG $\beta$ and FITC-labeled mouse anti-hMR and followed by donkey antirabbit IgG-Cy3 and goat anti-FITC/Oregon green-Alexa488. The images were taken using a confocal microscope. (c) Colocalization of hCG $\beta$ and $\mathrm{MHC}$ class II. Immunofluorescence dual staining was performed with rabbit anti-hCG $\beta$ and biotinylated anti-mouse $\mathrm{I}-\mathrm{A}^{\mathrm{b}}$ and followed by goat anti-rabbit IgG-Alexa488 and strepavidin-Cy3. The images were taken using a confocal microscope. hCG $\beta$, human chorionic gonadotropin beta chain; hMR-Tg, human mannose receptor transgenic; IHC, immunohistochemical; LN, lymph node; WT, wild-type.

\section{GM-CSF, but not poly-ICLC or CpG, upregulates MR expression}

One potential mechanism for adjuvant to enhance immunity of MR-targeted vaccine could be through changing MR expression, thus improving targeting efficiency. It has been reported that Th1/Th2 cytokines differentially regulated MR a
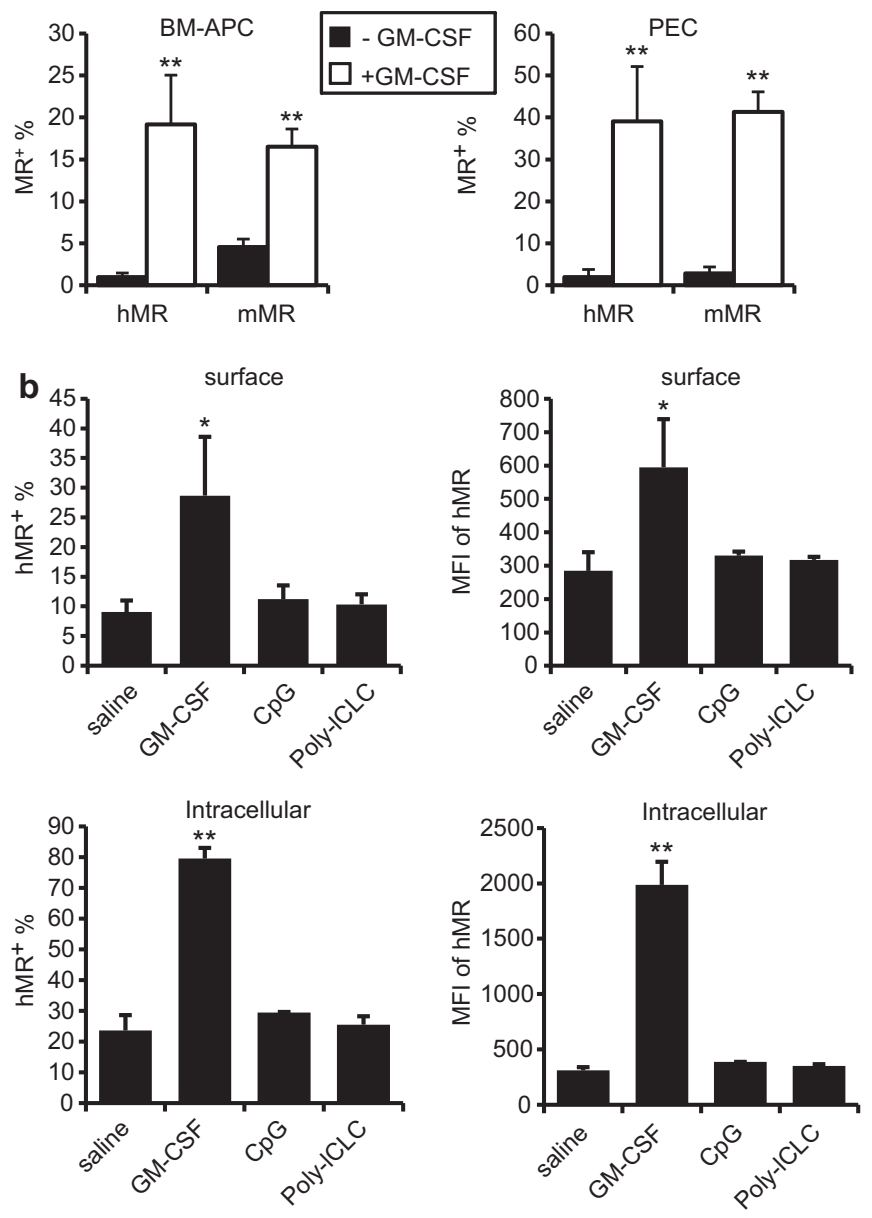

Figure 2 GM-CSF but not TLR agonists upregulated MR expression. (a) hMR-Tg mice were injected i.p. with $1 \mathrm{ml}$ of $3 \%$ thioglycolate on day 1 as well as minus or plus $2 \mu \mathrm{g}$ of GM-CSF on days $2-4$. PEC and BM were collected on day 5 and stained for flow cytometry with 19.2-PE (antihMR) or 5D3-PE (anti-mMR). The data shown are the mean \pm s.d. percentages of $\mathrm{MR}^{+}$cells in the APC-enriched BM and PEC of four mice per treatment pooled from two independent experiments. Student's $t$-test compared mice receiving thioglycolate plus or minus GM-CSF (** $P<0.01$ ). (b) hMR-Tg mice were injected i.p. with $1 \mathrm{ml}$ of $3 \%$ thioglycolate on day 1 . These mice subsequently received $2 \mu$ g of GM-CSF daily on days $2-4 ; 25 \mu \mathrm{g}$ of CpG on day $4 ; 20 \mu \mathrm{g}$ of poly-ICLC on day 4 ; or saline on day 4. PEC were collected on day 5 and stained for flow cytometry with19.2-PE and F4/80-APC-eFluor780, with or without permeabilization to distinguish intracellular or surface hMR. The data shown are the mean \pm s.d. of $\mathrm{hMR}^{+}$cells percentages (left) and MFI (right) in the PEC-M $\Phi$ of three mice per treatment. Student's $t$-test: $* P<0.05$, ${ }^{*} * P<0.01$, compared to thioglycolate plus saline injection. $\mathrm{BM}$, bone marrow; hMR-Tg, human mannose receptor transgenic; i.p., intraperitoneally; MFI, mean fluorescence intensity; PEC, peritoneal exudate cell; TLR, Toll-like receptor.

expression. ${ }^{24,27}$ GM-CSF is commonly used in the preparation of DCs in vitro, and is associated with high expression of MR in both human and mouse systems. ${ }^{28-31} \mathrm{MR}$ expression in human monocyte-derived-DC was diminished upon maturation induced by lipopolysaccharide, a TLR4 ligand. ${ }^{32}$ However, all these results were derived from in vitro observations, and the in 

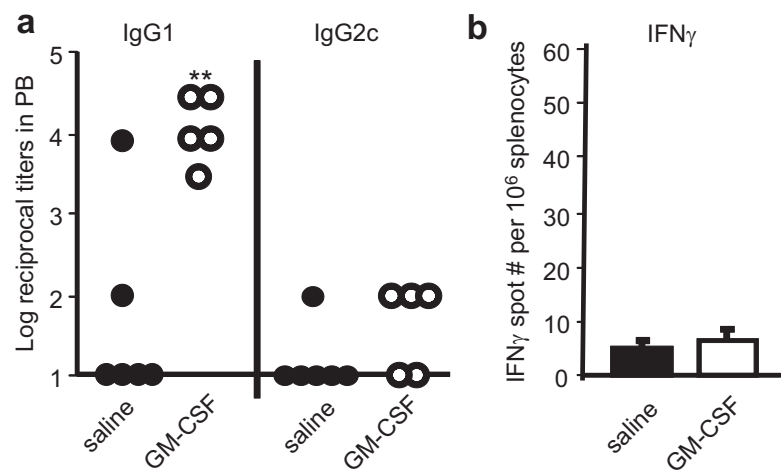

Figure 3 GM-CSF augmented IgG1 production, but not IgG2c nor IFN$\gamma$ production. hMR-Tg mice were injected twice i.p. with $1 \mu \mathrm{g}$ of B11hCG $\beta$ on days 3 and 17 , and also received $2 \mu$ g of GM-CSF or saline on days 1-4 and 15-18. (a) Anti-hCG $\beta$ titers in plasma and (b) hCG $\beta$ specific IFN- $\gamma$-ELISPOT counts from spleens were assessed on day 24 . Student's $t$-test: **P<0.01 compared between B11-hCG $\beta$ with or without GM-CSF. The results were reproduced in three independent experiments. hCG $\beta$, human chorionic gonadotropin beta chain; i.p., intraperitoneally; hMR-Tg, human mannose receptor transgenic.

vivo regulation of MR expression was not reported. To this end, we examined the expression level of the hMR transgene, as well as the endogenous $\mathrm{mMR}$, after administration with or without GM-CSF, poly-ICLC or CpG. As shown by flow cytometry, the percentage and the mean fluorescence intensity of hMR in APC-enriched BM cells and in PEC-M $\Phi$ derived from hMR$\mathrm{Tg}$ mice were significantly greater after GM-CSF treatment. The parallel increases in intracellular and surface hMR suggested upregulation and not simply translocation of hMR by GM-CSF (Figure 2). The endogenous mMR in APC-enriched BM cells and in PEC was also elevated in hMR-Tg and WT mice in response to GM-CSF (Figure $2 \mathrm{a}$ and data not shown). However, poly-ICLC or CpG treatment did not change the hMR expression level (in $24 \mathrm{~h}$, which was relevant to our targeting vaccination).

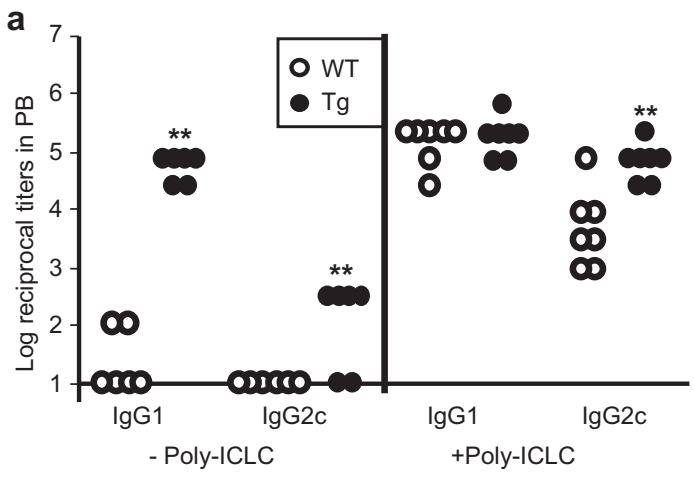

GM-CSF promotes a Th2 response to the B11-hCG $\beta$ vaccine We postulated that GM-CSF increased MR expression in vivo, and thereby enhanced the uptake and immune responses to MR-targeted vaccine. Therefore, we first tested the effect of GM-CSF on immune responses to B11-hCG $\beta$. At low doses of vaccine ( $1 \mu \mathrm{g} \times 2$ of B11-hCG $\beta$ ), GM-CSF pre-treatment was associated with consistently higher hCG $\beta$-specific IgG1 titers in the hMR-Tg mice (Figure 3a left panel). However, the same hCG $\beta$-specific IgG1 titers could also be achieved directly using higher doses of vaccine in the absence of GM-CSF $(2 \times 10 \mu \mathrm{g}$ of B11-hCG $\beta$; Figure 4a left panel). In addition, the immune response to the B11-hCG $\beta$ vaccine with GM-CSF treatment was Th2-biased, as revealed by the lack of significant IgG2c titer or IFN- $\gamma$-producing $\mathrm{T}$ cells (Figure $3 \mathrm{a}$ right panel and $\mathrm{b}$ ).

\section{Poly-ICLC improves Th1 responses to the B11-hCG $\beta$} vaccine, and combined TLR agonists further enhance the immunity

Previous studies have documented the superior activity of double-stranded RNA as an adjuvant to improve the Th1 immunity of DEC-205-targeted vaccines, ${ }^{10,33}$ partially due to TLR3 agonistic activity. Accordingly, we investigated the ability of a stabilized poly-IC adjuvant (poly-ICLC) to enhance Th1 immune responses to B11-hCG $\beta$. In the absence of adjuvant, immunizations with B11-hCG $\beta$ ( $10 \mu \mathrm{g} \times 2$ of B11-hCG $\beta)$ elicited significantly higher IgG1 titers in hMR-Tg mice compared to WT mice, but relatively poor IgG2c titers and no significant IFN- $\gamma$ induction from splenocytes stimulated with hCG $\beta$ peptides (Figure 4). Co-administration of poly-ICLC induced titers of hCG $\beta$-specific IgG1 and IgG2c in all mice, with significantly higher IgG2c titers when hCG $\beta$ was targeted to the human MR in the transgenic mice (Figure 4a). Consistent with humoral responses, the number of hCG $\beta$-specific IFN- $\gamma$-producing splenocytes was increased by poly-ICLC, was significantly higher when the antigen was targeted to MR in the transgenic mice, and was further boosted by a secondary administration (Figure $4 \mathrm{~b}$ ).

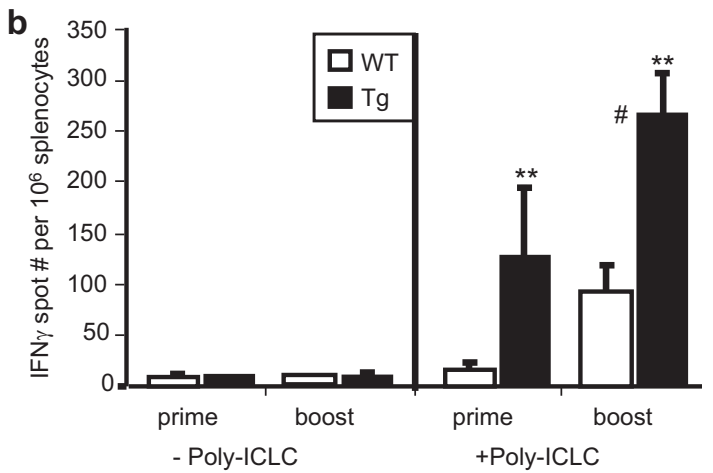

Figure 4 Poly-ICLC facilitated Th1 responses to hMR-targeted vaccine. hMR-Tg and WT mice were injected i.p. once (prime) with $10 \mu \mathrm{g}$ of B11hCG $\beta$ with or without $20 \mu \mathrm{g}$ of poly-ICLC, or twice (boost) at a 2 -week interval. (a) Anti-hCG $\beta$ antibody titers in plasma collected 1 week after the boost are shown. Student's $t$-test showed a significant difference between Tg and WT mice $(* * P<0.01)$ where indicated. The results were reproduced in three independent experiments. (b) hCG $\beta$-specific IFN- $\gamma$-ELISPOT counts in spleens collected 14 days after prime or after boost are shown. The means \pm s.d. were from five mice per group. For the groups receiving poly-ICLC, a Student's $t$-test showed significant differences between Tg and WT ( $* * P<0.01)$ and between boost and prime $\left({ }^{\#} P<0.01\right)$. The results were reproduced in two independent experiments. hCG $\beta$, human chorionic gonadotropin beta chain; i.p., intraperitoneally; hMR-Tg, human mannose receptor transgenic; WT, wild-type. 

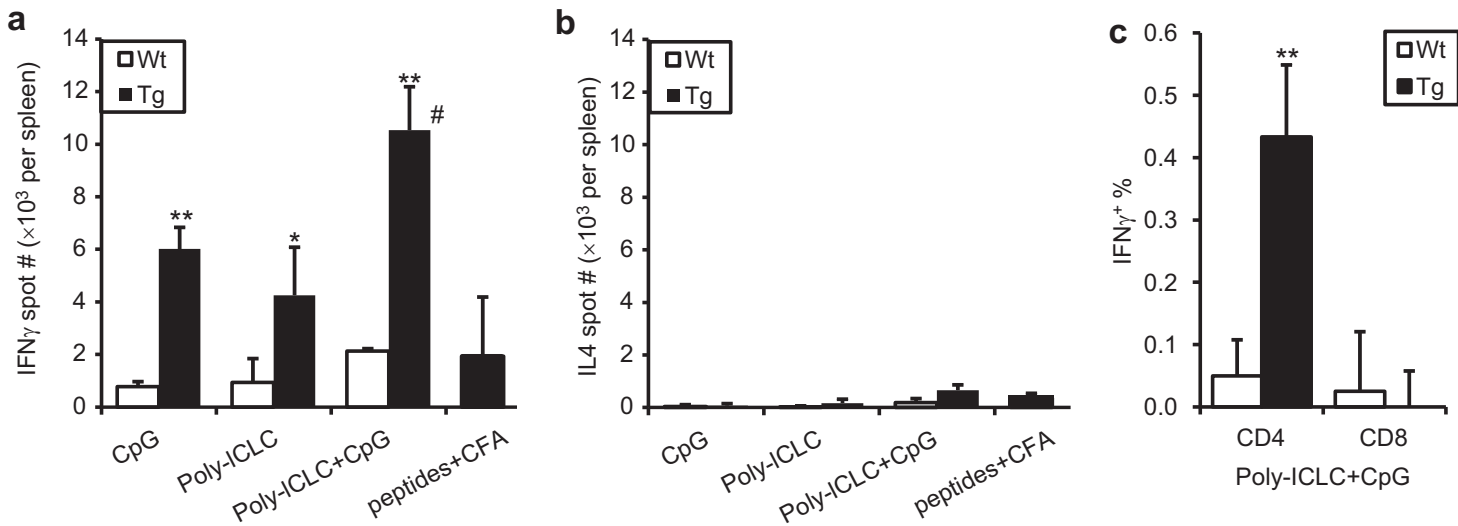

Figure 5 Th1 response to hMR-targeted vaccine was enhanced by the combination of TLR agonists. hMR-Tg and WT mice were injected s.c. in the paws with $10 \mu \mathrm{g}$ of B11-hCG $\beta$ plus $25 \mu \mathrm{g}$ of $\mathrm{CpG}$ and/or $20 \mu \mathrm{g}$ of poly-ICLC as indicated. The hCG $\beta$ overlapping peptide pool (100 $\mu \mathrm{g}$ per peptide $\times 34$ peptides per mouse) was emulsified with CFA and injected via same route in Tg mice for a comparison. Spleens were collected 14 days post-injection. Mean \pm s.d. of hCG $\beta$-specific (a) IFN- $\gamma$-ELISPOT and (b) IL-4-ELISPOT numbers per spleen and (c) IFN- $\gamma^{+}$percentage in $\mathrm{CD}^{+}{ }^{+}$and $\mathrm{CD}^{+}{ }^{+} \mathrm{T}$ cells from three mice per group are shown. Student's $t$-test: $* P<0.05$ and $* * P<0.01$ compared Tg with WT; ${ }^{\#} P \leqslant 0.01$ compared combined adjuvant with either single adjuvant or peptides+CFA in Tg. The results were reproduced in two independent experiments. CFA, complete Freund's adjuvant; hCG $\beta$, human chorionic gonadotropin beta chain; hMR-Tg, human mannose receptor transgenic; s.c., subcutaneously; WT, wild-type.

To further enhance the Th1 immune response to the human MR-targeted vaccine, we tested CpG in combination with polyICLC. Similar to poly-ICLC, CpG alone induced a potent hCG $\beta$-specific IFN- $\gamma$ response in hMR-Tg mice when admixed with the vaccine. A further augmented response was achieved when the two TLR agonists were combined with the vaccine (Figure 5a). The response to vaccination was Thl-biased as TLR agonists neither alone nor in combination as adjuvant induced significant levels of the Th2 cytokine, IL-4 (Figure 5b). As dosed in this study, the B11-hCG $\beta$ combinations with TLR agonist(s) were also more effective in generating Th1 responses (IFN- $\gamma$ ) compared to overlapping hCG $\beta$ peptides emulsified in CFA (Figure 5a). To characterize the IFN- $\gamma$-producing splenocytes, intracellular IFN- $\gamma$ staining in conjunction with cell surface markers was performed and demonstrated that the hCG $\beta$-specific IFN- $\gamma$-producing splenocytes were predominantly $\mathrm{CD} 4^{+}$ $\mathrm{T}$ cells (Figure $5 \mathrm{c}$ ). No detectable $\mathrm{CD} 8^{+} \mathrm{T}$-cell responses were most likely due to a lack of $\mathrm{H}-2^{\mathrm{b}}$ haplotype MHC class I-restricted epitopes in the hCG $\beta$ molecule. This may not be relevant to hMR-targeting, since the hCG $\beta$ peptide pool emulsified in CFA also did not elicit $\mathrm{CD} 8^{+} \mathrm{T}$-cell responses (data not shown), whereas separate experiments targeting ovalbumin to hMR in combination with CPG did indeed induce potent $\mathrm{CD} 8{ }^{+}$CTL and antitumor activity. ${ }^{19}$

Lack of TLR agonist during priming with B11-hCG $\beta$ induces antigen-specific tolerance

We investigated the possibility that targeting human MR in the absence of adjuvants may induce tolerance as has been reported for targeting antigen to DCs through DEC-205. ${ }^{5,7}$ As shown in Figure $6 \mathrm{a}$, in hMR-Tg mice that were primed with B11-hCG $\beta$ alone, there was an attenuated T-cell response to a subsequent immunization, even when the boost was admixed with polyICLC and CpG (G3). In addition, B11-hCG $\beta$ without adjuvant was unable to significantly boost the response after priming with B11-hCG $\beta$ and adjuvant (G4). Mice that received both prime and boost vaccinations containing poly-ICLC and CPG showed a dramatic increase in the IFN- $\gamma$-ELISPOT number (G5), indicating that hMR-targeted vaccines required concomitant immune activation, such as that generated by TLR agonists for optimal cellular responses to the targeted antigen. In contrast to the effect on the T-cell responses, the lack of adjuvant did not significantly reduce the anti-hCG $\beta$ IgG1 titers in the boosted mice. However, a TLR agonist in the priming immunization was required for optimal anti-hCG $\beta$ IgG2c titers (Figure 6b).

\section{TLR agonists augment the number and distribution of vaccine-loaded DCs in draining lymph nodes following B11- hCG $\beta$ vaccination}

To gain more insight into the mechanism of enhanced Th1 immunity using the TLR agonists, we studied the effect of adjuvants on the frequency of total DCs and of vaccinecontaining DCs in the draining lymph nodes following immunization. WT or hMR-Tg mice were injected s.c. with Alexa 647-labeled B11-hCG $\beta$ in the presence or absence of TLR agonists, and flow cytometry analysis was performed $24 \mathrm{~h}$ later. Addition of poly-ICLC alone or together with CpG dramatically increased the overall number of mature DCs (defined as CD11 $\mathrm{c}^{\mathrm{hi}} \mathrm{MHC} \mathrm{II}^{\mathrm{hi}}$ ) in draining lymph nodes of both hMR-Tg and WT mice, resulting in elevated B11-hCG $\beta$ measurable cells compared to vaccine alone, respectively (Figure $7 \mathrm{a}$ and $\mathrm{b}$, absolute numbers and \%). However, B11-hCG $\beta$ measurable cells were at least threefold increased in draining lymph nodes of hMR-Tg compared to WT mice upon administration of each vaccine regimen, as shown by hCG $\beta^{+} \%$ in the DC gate (Figure $7 \mathrm{a}$ ) and by specifically gating on B11-hCG $\beta$-positive cells (Figure 7b). 
a

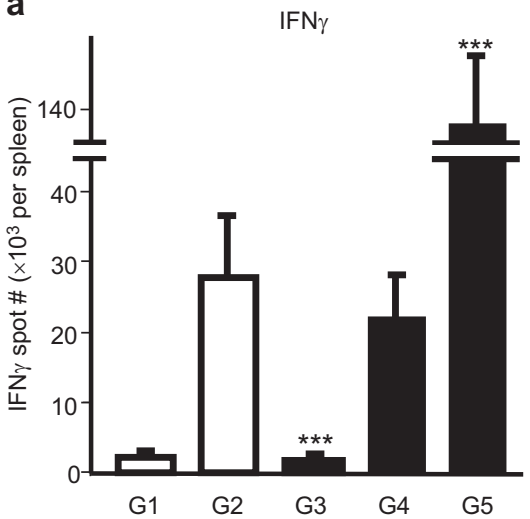

b

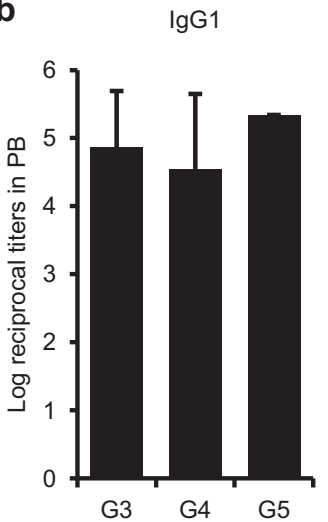

$\lg G 2 c$

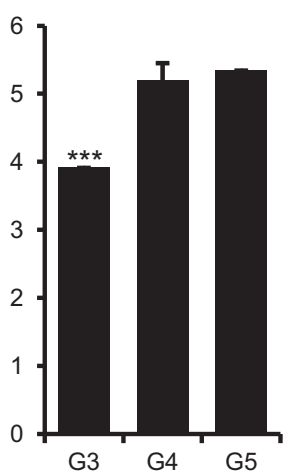

Figure 6 MR-targeted vaccine alone induced Th1 but not Th2 unresponsiveness. hMR-Tg mice were immunized s.c. in the paws with one or two doses of $10 \mu \mathrm{g}$ of B11-hCG $\beta$ at a 26-day interval in the absence or presence of $20 \mu \mathrm{g}$ of poly-ICLC and $25 \mu \mathrm{g}$ of CpG as labeled for the following groups: G1: prime with B11-hCG $\beta$ alone; G2: prime with B11-hCG $\beta+$ poly-ICLC+CpG; G3: prime with B11-hCG $\beta$, boost with B11-hCG $\beta+$ polyICLC+CpG; G4: prime with B11-hCG $\beta+$ poly-ICLC+CpG, boost with B11-hCG $\beta$; G5: prime and boost with B11-hCG $\beta+C p G+$ poly-ICLC. Blood and spleens were collected 7 days after the first or second injection. Means \pm s.d. of (a) hCG $\beta$-specific IFN- $\gamma$-ELISPOT numbers and (b) IgG1 and IgG2c titers from three mice per treatment are shown. Mice receiving a single immunization (G1 and G2) did not generate titers and are not included in (b). Student's $t$-test: $* * * P<0.001$ compared G3 or G5 with G4. Similar results were obtained from repeated experiments. hCG $\beta$, human chorionic gonadotropin beta chain; hMR-Tg, human mannose receptor transgenic; s.c., subcutaneously; WT, wild-type.

The increased hCG $\beta^{+}$cells were dual stained with hMR (Figure $7 \mathrm{a}$ ), indicating the greater accumulation of targeted vaccine was indeed hMR-mediated. Further characterization of the B11-hCG $\beta^{+}$DCs confirmed that they were both hMR- and mMR-positive and distinct from the classic DEC $-205^{+}$or $\mathrm{CD}_{103}{ }^{+}$DCs (Figure $7 \mathrm{c}$ ).

We further studied the effect of adjuvants on the B11hCG $\beta$ vaccine by investigating the localization of hCG $\beta$-containing cells by immunohistochemistry in hMR-Tg mice (Figure 8). CD3e and B220 immunofluorescence staining in draining lymph nodes derived from hMR-Tg mice revealed that the $\mathrm{T}$ - and $\mathrm{B}$-cell distribution was consistent with the well-accepted pattern, i.e., $\mathrm{T}$ cells predominantly located in paracortex and deep cortex regions (Figure 8a). As noted previously, the non-adjuvanted B11-hCG $\beta$ was localized primarily in the subcapsular and medullar areas with only a few scattered clusters observed in the paracortex of the draining lymph nodes. GM-CSF treatment resulted in an increased intensity of hCG $\beta$ staining, consistent with the increased MR expression, but these cells remained predominantly in non-T-cell areas. However, upon the co-administration of poly-ICLC with B11-hCG $\beta$, a marked increase in the numbers of hCG $\beta^{+}$cells was seen in the paracortical and deep cortex $\mathrm{T}$ cell regions. The staining intensity of hCG $\beta$ appeared somewhat diminished in the lymph nodes of animals treated with the combination of poly-ICLC and CpG. Clearly, adjuvants can impact the number of APCs and their localization in peripheral lymph nodes.

\section{DISCUSSION}

Improving protein-based immunization remains a major objective for generating more effective vaccines. One approach that has been widely pursued in preclinical models involves attaching antigens to antibodies specific for DC surface molecules. ${ }^{8}$ Such antibody-targeted vaccines have shown high efficiency in promoting antigen uptake, processing and presentation through both MHC class I and MHC class II pathways. ${ }^{3,15,19}$ Our studies, using an MR-specific antibody fused to the oncofetal cancer antigen hCG $\beta$ (B11-hCG $\beta$ ) showed that when combined with DC activation, the vaccine could elicit $\mathrm{T}$ cells in vitro that resulted in specific lysis of HLA-matched tumor cells naturally expressing the antigen. ${ }^{23}$ Subsequently, we translated this approach into a phase 1 clinical study, which confirmed the feasibility, safety and immunogenicity of the B11-hCG $\beta$ vaccine in cancer patients. ${ }^{22}$ The study reported here provided a better understanding of the effects of adjuvants (GM-CSF, poly-ICLC and CpG) on the B11-hCG $\beta$ vaccine using mice engineered to express human MR.

A humoral response could be elicited in hMR-Tg mice by B11-hCG $\beta$ immunization independent of adjuvant, which is consistent with reported results where the $\mathrm{CD} 8^{-}$DC subset was targeted via FIRE (F4/80-like receptor) and CIRE (C-type lectin receptor) in the absence of a conventional 'danger' signal. ${ }^{34}$ We demonstrate that GM-CSF augments IgG1 titers (at low doses of vaccine), presumably due to the increase of MR expression induced on APCs. However, Th1 responses were only elicited by B11-hCG $\beta$ immunization in combination with the DC activation reagents, poly-ICLC and/or CpG. In fact, in the absence of the DC activators, B11-hCG $\beta$ led to T-cell irresponsiveness, as subsequent boosting even with TLR agonists generated a significantly muted response compared to controls.

Using flow cytometry, we found an increase ( $>$ fourfold) in the number of CD11 $\mathrm{c}^{\mathrm{hi}} \mathrm{MHC} \mathrm{II}^{\mathrm{hi}}$ DCs in draining lymph nodes of both hMR-Tg and WT mice vaccinated with poly-ICLC or the combination of poly-ICLC and CpG. This finding is consistent with the induction of DC migration to lymph nodes 

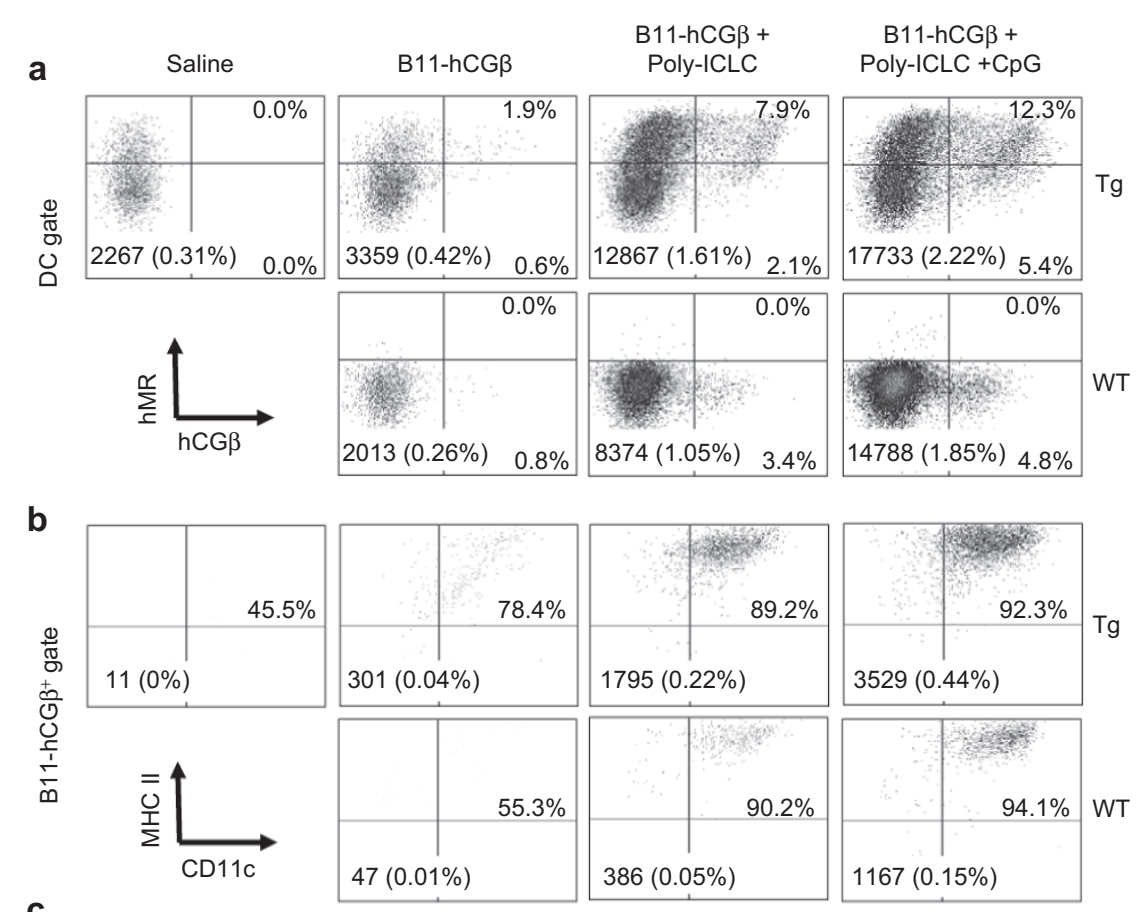

C
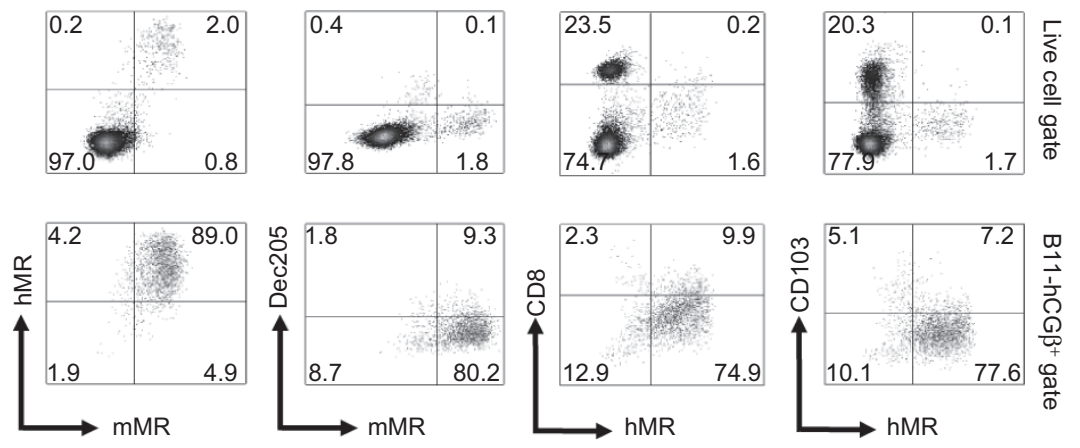

Figure 7 TLR agonists increased B11-hCG $\beta$-containing mature DCs in draining lymph nodes. hMR-Tg and WT mice were injected s.c. in the paws with $20 \mu \mathrm{g}$ of Alexa 647-labeled B11-hCG $\beta \pm$ adjuvant as indicated at the same doses as in Figure 2. Draining lymph nodes were collected $24 \mathrm{~h}$ later and pooled. Cells were stained with Pacific Blue fluorescence dye, anti-CD11c and anti-MHC II. A total 800000 events were acquired. (a) B11-

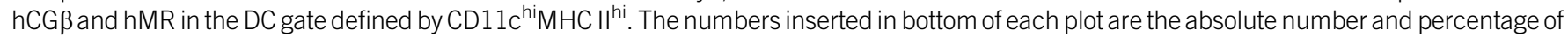
the mature DC among total acquired live lymph node cells. (b) CD11c and MHC II in B11-hCG $\beta$-positive cell gate. The numbers inserted in the bottom of each plot are the absolute number and percentage of B11-hCG $\beta$-positive cells among total acquired live lymph node cells. (c) The LN cells were also stained with $\mathrm{mMR}$ and hMR, mMR and Dec205, hMR and CD $8 \alpha$ or hMR and CD103. The staining among gated live cells and hCG $\beta^{+}$ cells upon injection with B11-hCG $\beta$-alexa 647+poly-ICLC+CpG in hMR-Tg mice is shown. The data are representative of three independent experiments. hCG $\beta$, human chorionic gonadotropin beta chain; hMR-Tg, human mannose receptor transgenic; s.c., subcutaneously; TLR, Tolllike receptor.

upon activation. ${ }^{26,35,36}$ The B11-hCG $\beta$ vaccine was found predominantly in this DC population. In the hMR-Tg mice, the accumulation of vaccine in DCs was significantly greater than in WT mice, and was exclusively observed in $\mathrm{hMR}^{+} \mathrm{DEC}$ $205^{-}$CD $103^{-}$DCs.

The distribution of the B11-hCG $\beta$ vaccine upon subcutaneous administration in hMR-Tg mice was substantially impacted by combination with adjuvants. In the absence of adjuvants, the hCG $\beta^{+}$cells showed the same distribution pattern as transgenic hMR and endogenous mMR. ${ }^{19,25}$ The vaccine-positive cells were predominantly MHC class $\mathrm{II}^{+}$, yet some vaccine was also observed in
MHC class $\mathrm{II}^{-}$cells, which could possibly represent a less mature APC with the potential for tolerance induction in the absence of adjuvants. Nevertheless, co-administration of poly-ICLC with B11-hCG $\beta$ led to a remarkable accumulation of vaccine containing cells within the T-cell zones of the lymph nodes. These $\mathrm{MR}^{+}$B11-hCG $\beta$-containing DCs in the T-cell zones may be similar to the monocytederived DC-SIGN ${ }^{+}$T-cell area DCs described by Cheong et al., ${ }^{36}$ i.e., fully functional with strong cross-presentation activity and high expression of MR. In the Cheong et al.'s paper, however, the expansion of this population was induced by lipopolysaccharide or Gram-negative bacteria, 
a

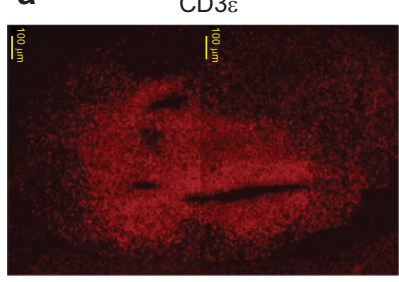

b
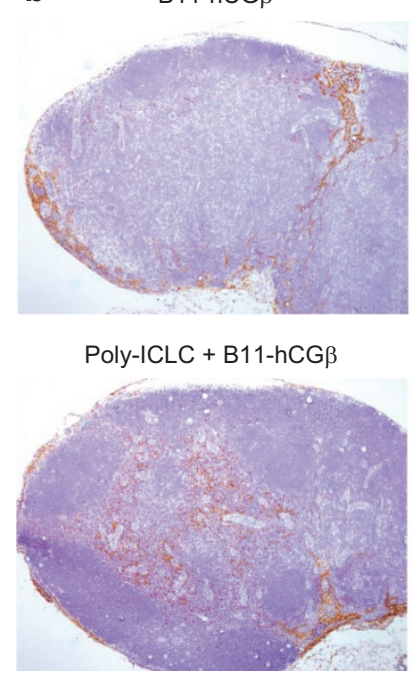

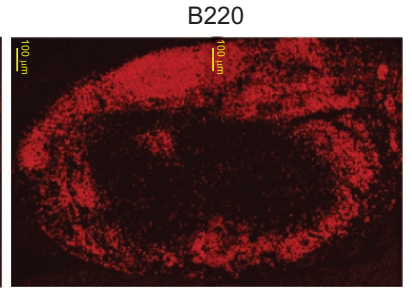

$\mathrm{GM}-\mathrm{CSF}+\mathrm{B} 11-\mathrm{hCG} \beta$

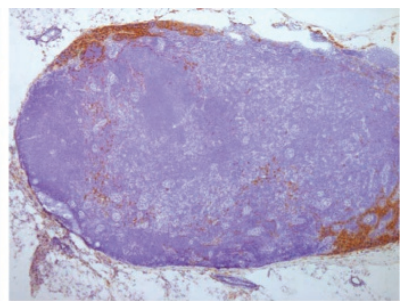

Poly-ICLC + CpG+B11-hCG $\beta$

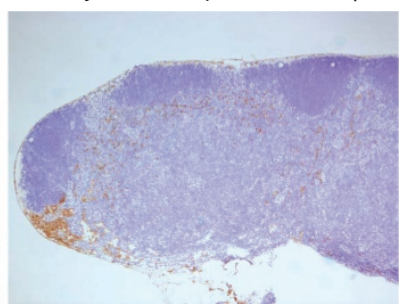

Figure 8 TLR agonists promoted the accumulation of B11-hCG $\beta$-containing cells in the T-cell area of draining lymph nodes. hMR-Tg mice were injected s.c. at the tail base with $10 \mu \mathrm{g}$ of B11-hCG $\beta \pm \mathrm{GM}-\mathrm{CSF}$, poly-ICLC and CpG as indicated at the same doses as in Figure 2. Inguinal lymph nodes were collected $24 \mathrm{~h}$ later. Cryopreserved sections were stained with (a) anti-CD3ع-Texas red or anti-B220-Texas red; (b) rabbit anti-hCG $\beta$ and followed with EnVision kit and hematoxylin counterstains. The images were taken with a $\times 4$ objective lens. hCG $\beta$, human chorionic gonadotropin beta chain; hMR-Tg, human mannose receptor transgenic; s.c., subcutaneously.

but not by any other TLR agonists tested, including poly-IC or CpG. Alternatively, it is very possible that the remarkable accumulation of vaccine-containing DCs in T-cell zones results from B11-hCG $\beta$-loaded APC migration from local skin to the paracortex region of the draining lymph nodes. Using a rat anti-mMR mAb, McKenzie et al. ${ }^{26}$ observed that by $24 \mathrm{~h}$ post-injection, $\mathrm{MR}^{+} \mathrm{MHC} \mathrm{II}^{+}$cells containing anti-MR $\mathrm{mAb}$ were detected within the paracortex and their frequency was remarkably increased following systemic or local stimulation with lipopolysaccharide and flagellin. The authors proposed that $\mathrm{MR}^{+}$macrophage-like cells in the dermis were potential precursors, and during their migration, $\mathrm{MR}^{+}$cells acquired a DC phenotype (increased MHC II expression) and lost a macrophage phenotype (CD68 downregulated). Therefore, $\mathrm{MR}^{+}$APC migration from peripheral tissues to the draining lymph node T-cell area and differentiation to fully mature DCs may be induced by a variety of TLR agonists. In our study, lower hCG $\beta$ staining intensity was observed with the combination of TLR agonists, poly-ICLC and CpG, which suggests either that different kinetics (tissue was collected only at $24 \mathrm{~h}$

post-vaccination in our study) or that alternate mechanisms may be involved.

Our recently reported clinical study demonstrated consistent humoral and T-cell responses to hCG- $\beta$ when the B11-hCG $\beta$ vaccine was co-administered with TLR agonists (poly-ICLC and/or resiquimod) compared to giving the vaccine alone. ${ }^{22,37}$ In general, the stronger immune responses and clinical benefit, including the longest duration of stable disease, were observed when immunization of the B11-hCG $\beta$ vaccine was combined with local TLR agonists. The small sample size and the significant variability in patient population with advanced cancer, however, preclude a definitive interpretation. Using our hMR-Tg mouse model, we have shown that indeed TLR agonists can have profound effects on the distribution and functional consequences of our MR-targeted vaccine. We have shown that DC activation through TLR agonists can prevent tolerance induction and drive Th1 immunity. We showed that GM-CSF treatment in combination with the B11-hCG $\beta$ vaccine, on the other hand, was limited to enhancing the Th2 humoral response. These results support the rational design of future clinical studies with B11-hCG $\beta$ and other MR-targeted vaccines in order to optimize protein-based immunization.

\section{ACKNOWLEDGEMENTS}

We would like to thank Naseem Prostak and James Testa for their contributions in some ELISPOT and flow cytometry analysis, Dr Yan Zhang for the IHC studies and Dr Xi-Tao Wang for the immunofluorescence staining. All authors are employees of Celldex Therapeutics, Inc.

1 Jiang W, Swiggard WJ, Heufler C, Peng M, Mirza A, Steinman RM et al. The receptor DEC-205 expressed by dendritic cells and thymic epithelial cells is involved in antigen processing. Nature 1995; 375: 151-155.

2 Bozzacco L, Trumpfheller C, Siegal FP, Mehandru S, Markowitz M, Carrington $\mathrm{M}$ et al. DEC-205 receptor on dendritic cells mediates presentation of HIV gag protein to $\mathrm{CD}^{+} \mathrm{T}$ cells in a spectrum of human MHC I haplotypes. Proc Natl Acad Sci USA 2007; 104: 1289-1294.

3 Cheong C, Choi JH, Vitale L, He LZ, Trumpfheller C, Bozzacco L et al. Improved cellular and humoral immune responses in vivo following targeting of HIV Gag to dendritic cells within human anti-human DEC205 monoclonal antibody. Blood 2010; 116: 3828-3838.

4 Tsuji T, Matsuzaki J, Kelly MP, Ramakrishna V, Vitale L, He LZ et al. Antibody-targeted NY-ESO-1 to mannose receptor or DEC205 in vitro elicits dual human $\mathrm{CD}^{+}$and $\mathrm{CD}^{+}{ }^{+} \mathrm{T}$ cell responses with broad antigen specificity. J Immunol 2011; 186: 12181227.

5 Bonifaz L, Bonnyay D, Mahnke K, Rivera M, Nussenzweig MC, Steinman RM. Efficient targeting of protein antigen to the dendritic cell receptor DEC-205 in the steady state leads to antigen presentation on major histocompatibility complex class I products and peripheral $\mathrm{CD}^{+} \mathrm{T}$ cell tolerance. J Exp Med 2002; 196: 1627-1638.

6 Bonifaz LC, Bonnyay DP, Charalambous A, Darguste DI, Fujii S, Soares $\mathrm{H}$ et al. In vivo targeting of antigens to maturing dendritic 
cells via the DEC-205 receptor improves T cell vaccination. J Exp Med 2004; 199: 815-824.

7 Hawiger D, Inaba K, Dorsett Y, Guo M, Mahnke K, Rivera M et al. Dendritic cells induce peripheral T cell unresponsiveness under steady state conditions in vivo. J Exp Med 2001; 194: 769-779.

8 Tacken PJ, de Vries IJ, Torensma R, Figdor CG. Dendritic-cell immunotherapy: from ex vivo loading to in vivo targeting. Nat Rev Immunol 2007; 7: 790-802.

9 Mahnke K, Qian Y, Fondel S, Brueck J, Becker C, Enk AH. Targeting of antigens to activated dendritic cells in vivo cures metastatic melanoma in mice. Cancer Res 2005; 65: 7007-7012.

10 Trumpfheller C, Caskey M, Nchinda G, Longhi MP, Mizenina O, Huang $Y$ et al. The microbial mimic poly IC induces durable and protective $\mathrm{CD}^{+}{ }^{+} \mathrm{T}$ cell immunity together with a dendritic cell targeted vaccine. Proc Natl Acad Sci USA 2008; 105: 2574-2579.

11 Ramakrishna V, Treml JF, Vitale L, Connolly JE, O'Neill T, Smith PA et al. Mannose receptor targeting of tumor antigen pmel17 to human dendritic cells directs anti-melanoma $T$ cell responses via multiple HLA molecules. J Immunol 2004; 172: 2845-2852.

12 Villadangos JA, Schnorrer P. Intrinsic and cooperative antigenpresenting functions of dendritic-cell subsets in vivo. Nat Rev Immunol 2007; 7: 543-555.

13 Dudziak D, Kamphorst AO, Heidkamp GF, Buchholz VR, Trumpfheller $\mathrm{C}$, Yamazaki S et al. Differential antigen processing by dendritic cell subsets in vivo. Science 2007; 315: 107-111.

14 Cruz LJ, Tacken PJ, Pots JM, Torensma R, Buschow SI, Figdor CG. Comparison of antibodies and carbohydrates to target vaccines to human dendritic cells via DC-SIGN. Biomaterials 2012; 33: 42294239.

15 Tacken PJ, de Vries IJ, Gijzen K, Joosten B, Wu D, Rother RP et al. Effective induction of naive and recall T-cell responses by targeting antigen to human dendritic cells via a humanized anti-DC-SIGN antibody. Blood 2005; 106: 1278-1285.

16 Tacken PJ, Ginter W, Berod L, Cruz LJ, Joosten B, Sparwasser T et al. Targeting DC-SIGN via its neck region leads to prolonged antigen residence in early endosomes, delayed lysosomal degradation, and cross-presentation. Blood 2011; 118: 4111-4119.

17 Idoyaga J, Cheong C, Suda K, Suda N, Kim JY, Lee H et al. Cutting edge: langerin/CD207 receptor on dendritic cells mediates efficient antigen presentation on $\mathrm{MHC} \mathrm{I}$ and II products in vivo. J Immunol 2008; 180: 3647-3650.

18 Schreibelt G, Klinkenberg LJ, Cruz LJ, Tacken PJ, Tel J, Kreutz M et al. The C-type lectin receptor CLEC9A mediates antigen uptake and (cross-)presentation by human blood $\mathrm{BDCA}^{+}$myeloid dendritic cells. Blood 2012; 119: 2284-2292.

19 He LZ, Crocker A, Lee J, Mendoza-Ramirez J, Wang XT, Vitale LA et al. Antigenic targeting of the human mannose receptor induces tumor immunity. J Immunol 2007; 178: 6259-6267.

20 Idoyaga J, Lubkin A, Fiorese C, Lahoud MH, Caminschi I, Huang Y et al. Comparable T helper 1 (Th1) and CD8 T-cell immunity by targeting HIV gag p24 to CD8 dendritic cells within antibodies to Langerin, DEC205, and Clec9A. Proc Natl Acad Sci USA 2011; 108: 2384-2389.

21 Chatterjee B, Smed-Sorensen A, Cohn L, Chalouni C, Vandlen R, Lee $\mathrm{BC}$ et al. Internalization and endosomal degradation of receptorbound antigens regulate the efficiency of cross presentation by human dendritic cells. Blood 2012; 120: 2011-2020.

22 Morse MA, Chapman R, Powderly J, Blackwell K, Keler T, Green J et al. Phase I study utilizing a novel antigen-presenting cell-targeted vaccine with Toll-like receptor stimulation to induce immunity to selfantigens in cancer patients. Clin Cancer Res 2011; 17: 4844-4853.

23 He LZ, Ramakrishna V, Connolly JE, Wang XT, Smith PA, Jones CL et al. A novel human cancer vaccine elicits cellular responses to the tumor-associated antigen, human chorionic gonadotropin beta. Clin Cancer Res 2004; 10: 1920-1927.

24 Taylor PR, Gordon S, Martinez-Pomares L. The mannose receptor: linking homeostasis and immunity through sugar recognition. Trends Immunol 2005; 26: 104-110.

25 Linehan SA, Martinez-Pomares L, Stahl PD, Gordon S. Mannose receptor and its putative ligands in normal murine lymphoid and nonlymphoid organs: in situ expression of mannose receptor by selected macrophages, endothelial cells, perivascular microglia, and mesangial cells, but not dendritic cells. J Exp Med 1999; 189: 1961-1972.

26 McKenzie EJ, Taylor PR, Stillion RJ, Lucas AD, Harris J, Gordon S et al. Mannose receptor expression and function define a new population of murine dendritic cells. J Immunol 2007; 178: 49754983.

27 McKenzie EJ, Su YP, Martinez-Pomares L. The mannose receptor, a bi-functional lectin with roles in homeostasis and immunity. Trends Glycosci Glycotechnol 2002; 14: 273-283.

28 Nigou J, Zelle-Rieser C, Gilleron M, Thurnher M, Puzo G. Mannosylated lipoarabinomannans inhibit IL-12 production by human dendritic cells: evidence for a negative signal delivered through the mannose receptor. J Immunol 2001; 166: 74777485.

29 Burgdorf S, Lukacs-Kornek V, Kurts C. The mannose receptor mediates uptake of soluble but not of cell-associated antigen for cross-presentation. J Immunol 2006; 176: 6770-6776.

30 Segura E, Albiston AL, Wicks IP, Chai SY, Villadangos JA. Different cross-presentation pathways in steady-state and inflammatory dendritic cells. Proc Natl Acad Sci USA 2009; 106: 2037720381.

31 Chieppa M, Bianchi G, Doni A, del Prete A, Sironi M, Laskarin G et al. Cross-linking of the mannose receptor on monocyte-derived dendritic cells activates an anti-inflammatory immunosuppressive program. $\mathrm{J}$ Immunol 2003; 171: 4552-4560.

32 Kato M, Neil TK, Fearnley DB, McLellan AD, Vuckovic S, Hart DN. Expression of multilectin receptors and comparative FITC-dextran uptake by human dendritic cells. Int Immunol 2000; 12: 15111519.

33 Longhi MP, Trumpfheller C, Idoyaga J, Caskey M, Matos I, Kluger C et al. Dendritic cells require a systemic type I interferon response to mature and induce $\mathrm{CD} 4{ }^{+} \mathrm{Th} 1 \mathrm{imm}$ unity with poly IC as adjuvant. J Exp Med 2009; 206: 1589-1602.

34 Corbett AJ, Caminschi I, McKenzie BS, Brady JL, Wright MD, Mottram PL et al. Antigen delivery via two molecules on the $\mathrm{CD}^{-}$dendritic cell subset induces humoral immunity in the absence of conventional "danger". Eur J Immunol 2005; 35: 2815-2825.

35 Zanoni I, Granucci F. Regulation of antigen uptake, migration, and lifespan of dendritic cell by Toll-like receptors. J Mol Med (Berl) 2010; 88: 873-880.

36 Cheong C, Matos I, Choi JH, Dandamudi DB, Shrestha E, Longhi MP et al. Microbial stimulation fully differentiates monocytes to DC-SIGN/CD209 ${ }^{+}$dendritic cells for immune $T$ cell areas. Cell 2010; 143: 416-429.

37 Morse MA, Bradley DA, Keler T, Laliberte RJ, Green JA, Davis TA et al. CDX-1307: a novel vaccine under study as treatment for muscleinvasive bladder cancer. Expert Rev Vaccines 2011; 10: 733-742.

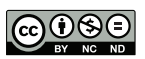

This work is licensed under a Creative Commons Attribution-

NonCommercial-NoDerivs 3.0 Unported License. The images or other third party material in this article are included in the article's Creative Commons license, unless indicated otherwise in the credit line; if the material is not included under the Creative Commons license, users will need to obtain permission from the license holder to reproduce the material. To view a copy of this license, visit http://creativecommons.org/licenses/by-nc-nd/3.0/ 